\title{
Pneumomediastinum and Pneumoperitoneum after Blunt Chest Trauma: The Macklin Effect
}

Marco Assenza ${ }^{1 *}$, Fabiola Passafium ${ }^{2}$, Lorenzo Valesini ${ }^{1}$, Leonardo Centonze ${ }^{1}$, Valentina Romeo ${ }^{1}$ and Claudio Modini ${ }^{1}$

${ }^{1}$ Emergency Department, Division of Emergency Surgery and Trauma, Policlinico "Umberto I", University of Rome "Sapienza", Umberto I General Hospital, Rome, Italy ${ }^{2}$ Surgery Department Pietro Valdoni, Policlinico "Umberto I" University of Rome "Sapienza", Umberto I General Hospital, Rome, Italy

\begin{abstract}
Background: Pneumomediastinum creation, in blunt chest trauma, results from Mackin effect in more than 95\% of cases.

Objectives: In this article we report two cases of blunt chest trauma, underlining the relationship between Macklin effect, pneumomediastinum and pneumoperitoneum, and analysing conservative and invasive treatment.

Case reports: We report two cases of blunt chest trauma with Pneumomediastinum creation and no evidence of airway lesions. The first patient presented with malignant pneumomediastinum, created by Macklin effect, and pneumoperitoneum with intra-abdominal hypertension. He underwent invasive treatment.

The second case shows how Macklin effect can be self-limiting. This patient underwent conservative treatment.

Conclusions: In any case of post-traumatic pneumomediastinum, the Macklin effect should be suspected. Clinical observation is the treatment of choice since Macklin effect is self-limiting. There are some life-threatening event, like malignant pneumomediastinum and intra-abdominal hypertension that must be relieved and treated immediately.
\end{abstract}

Keywords: Macklin effect; Pneumomediastinum; Pneumoperitoneum; Blunt chest trauma

\section{Introduction}

Pneumomediastinum (from Greek pneuma "air") is defined as the presence of free air around mediastinal structures and it is also known as mediastinal emphysema.

Pneumomediastinum can be divided into two groups: Spontaneous Pneumomediastinum, without any obvious primary source, originally described by Hamman [1] and for this reason called Hamman's syndrome; and Secondary Pneumomediastinum, with a clear pathologic event, first described by Laennec in a case of chest trauma [2].

The clinical diagnosis of Pneumomediastinum is based on two particular symptoms, chest pain and dyspnea, and a peculiar sign, subcutaneous emphysema. Other signs and symptoms associated are secondary to tissue dissection or compression by air (including cough, rhinolalia, dysphagia, cervical pain, anxiety, pneumothorax, pneumoretroperitoneum and pneumoperitoneum) [3].

We report two cases of pneumomediastinum treated in our Emergency Department.

\section{Case 1}

A 24-year-old man involved in a high speed motor vehicle collision was transferred to the nearest level I Emergency Department where he arrived unconscious with blood pressure of 100/60 $\mathrm{mmHg}$ and blood oxygen desaturation (56\%). On physical examination he was gasping, pale with multiple wounds on face and head. His Glasgow Coma Scale (GCS) score on arrival was 3 and he was immediately intubated.

A total body Computed Tomography (CT) scan was performed revealing a subdural hematoma, maxillary sinus hematoma, right clavicle fracture, traumatic hemothorax with diffuse pulmonary contusions. He was thus transferred to our Level I Emergency Department.

When he arrived at our department his vital signs were: Blood Pressure (BP) 90/60 mmHg; Heart Rate (HR) 100 bpm; $\mathrm{O}_{2}$ Saturation $\left(\mathrm{O}_{2}\right.$ Sat) 43\%; $\mathrm{O}_{2}$ Pressure $\left(\mathrm{O}_{2} \mathrm{P}\right) 30 \mathrm{mmHg}$; $\mathrm{CO}_{2}$ Pressure $\left(\mathrm{CO}_{2} \mathrm{P}\right) 71$ mmHg; pH 7.21; blood glucose $225 \mathrm{mg} / \mathrm{dl}$. The patient was ventilated by a Synchronized Intermittent Mandatory Ventilation (SIMV) with $\mathrm{FiO}_{2} 100 \%$ and PEEP of 10 . Two $32 \mathrm{Fr}$ thoracic drains were inserted to drain both pleural spaces. They drained blood with a low evidence of air loss. He underwent a new CT scan which confirmed the first result but, in addition, demonstrated fracture of the dens epistropheus, small right-side pneumothorax (Figure 1), peritracheal pneumomediastinum with associated subcutaneous emphysema, rib fractures (VI,VII) and air in anterior abdominal region. In order to identify the cause of mediastinal air a flexible bronchoscopy was performed, with no evidence of bronchotracheal injury.

The patient's conditions worsened (BP $70 / 30 \mathrm{mmHg}$, HR 130 bpm) and a further CT scan showed an increase of mediastinal air that extended to retroperitoneal region and through neck sheaths (Figure 2\&3). The intra-abdominal pressure, measured indirectly by measuring pressure within the bladder, was $40 \mathrm{~cm} \mathrm{H}_{2} \mathrm{O}$. An explorative and

*Corresponding author: Marco Assenza, Emergency Department, Division of Emergency Surgery and Trauma, Policlinico "Umberto I", University of Rome, Via Demetriade 58, Rome 00178, Italy, E-mail: marco.assenza@uniroma1.it

Received December 09, 2011; Accepted January 06, 2012; Published January 10, 2012

Citation: Assenza M, Passafiume F, Valesini L, Centonze L, Romeo V, et al. (2012) Pneumomediastinum and Pneumoperitoneum after Blunt Chest Trauma: The Macklin Effect. J Trauma Treatment 1:107. doi:10.4172/2167-1222.1000107

Copyright: @ 2012 Assenza M, et al. This is an open-access article distributed under the terms of the Creative Commons Attribution License, which permits unrestricted use, distribution, and reproduction in any medium, provided the original author and source are credited. 
Citation: Assenza M, Passafiume F, Valesini L, Centonze L, Romeo V, et al. (2012) Pneumomediastinum and Pneumoperitoneum after Blunt Chest Trauma: The Macklin Effect. J Trauma Treatment 1:107. doi:10.4172/2167-1222.1000107

decompressive laparotomy was immediately performed. A laparostomy was created to prevent abdominal compartment syndrome (ACS) and improve respiratory movements. Free gas and serosanguinous fluid were found in the peritoneal cavity. Despite that, full examination of the viscera did not reveal evidence of bowel perforation. A $32 \mathrm{Fr}$ mediastinal drainage was placed during the same procedure (Figure $4 \& 5)$. After these procedures saturation rose $(85 \%)$ and vital signs became stable (BP 135/75 mmHg; HR 90 bpm; $\mathrm{O}_{2} \mathrm{P} 53$ mmHg; $\mathrm{CO}_{2} \mathrm{P}$ $45 \mathrm{mmHg}$; $\mathrm{pH}$ 7.34). The patient was transferred to intensive care unit.

Four days after the surgical procedure, further CT scan and bronchoscopic evaluation were performed. Both of them, associated with hemodynamic stability, allowed laparostomy closure.

On the 10th and 11 th postoperative day the thoracic drainages were removed. Other CT scans (Figure 6) and flexible bronchoscopies were performed and the mediastinal tube was taken out 14 days from insertion.

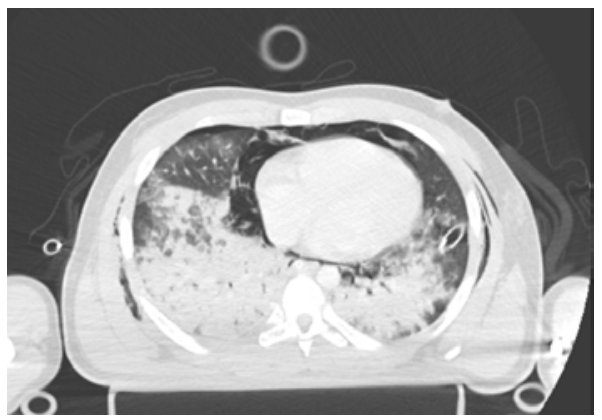

Figure 1: First CT control: small right-side pneumothorax, pneumomediastinum and subcutaneous emphysema.

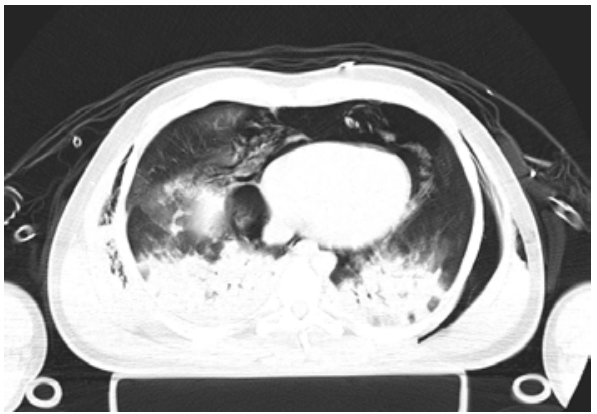

Figure 2: CT scan control showing an increase of mediastinal air

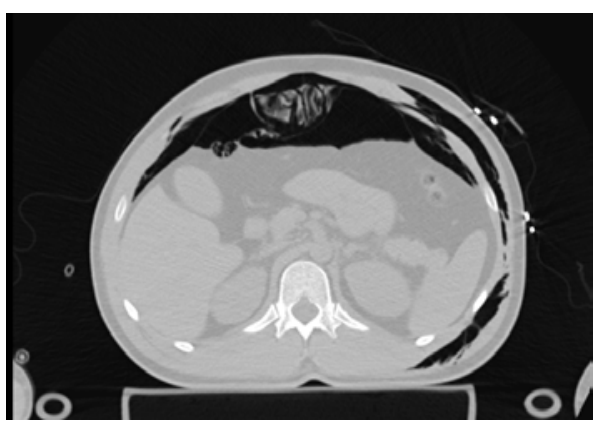

Figure 3: Pneumoperitoneum.

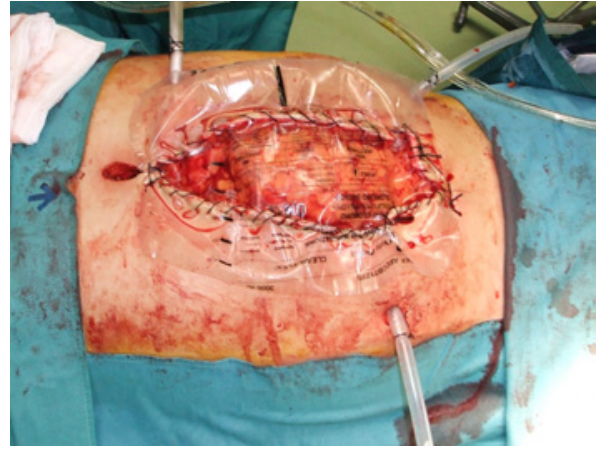

Figure 4: Mediastinal and thoracic drainages.

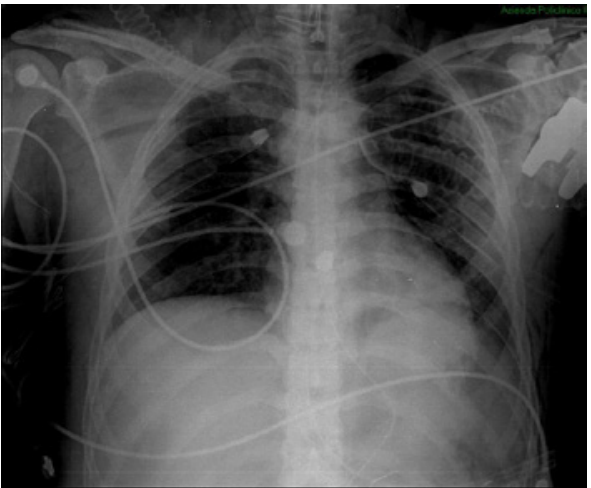

Figure 5: Pneumomediastinum, pneumothorax and pulmory contusions reduction.

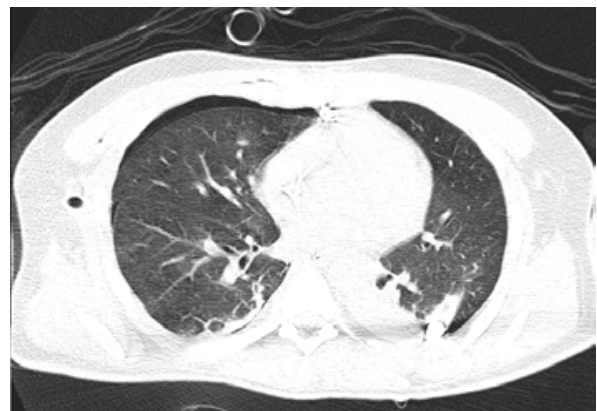

Figure 6: Pneumomediastinum and subcutaneous emphysema.

After a few days, the patient showed a temperature elevation with sepsis and a pulmonary infection. For that reason a specific antibiotic therapy was started and the patient underwent a tracheotomy procedure. General conditions started improving and the temporary tracheostomy was closed after about 20 days.

The fracture of the dens epistropheus was conservatively treated with Halo vest cervical collar.

After forty-five days GCS score returned to 15 and the patient was transferred to a rehabilitation clinic in quite good general condition.

\section{Case 2}

A 20 year-old man was transferred to our Emergency Department complaining of thoracic pain and voice alteration after sternal trauma during a football match. 
His general condition was good, with a GCS score of 15 . Vital signs were stable (BP 115/80 mmHg; HR 80 bpm; $\mathrm{O}_{2}$ Sat 100\%; $\mathrm{O}_{2} \mathrm{P} 98$ mmHg; $\mathrm{CO}_{2} \mathrm{P} 36$ mmHg; pH 7.39).

He showed subcutaneous emphysema in the chest and neck region, cough, dysphonia, with no dyspnea or jugular turgor.

He showed an increase in myocytolysis enzymes without no evidence of cardiac failure.

He underwent a chest X-ray and a thorax CT scan which showed pneumomediastinum and subcutaneous emphysema on the thoracic wall, cervical and subscapular region, while neither showed evidence of pleural effusion nor chest wall fractures (Figure 7).

This clinical presentation suggested a tracheal injury. For that reason, a flexible bronchoscopy was performed but showed no airway lesions.

He was admitted to our division for clinical observation. After 3 days he underwent a new thoracic CT scan showing the reduction of pneumomediastinum and one small left pulmonary contusion without pleural and pericardial effusion (Figure 8\&9).

He was discharged after 4 days, in good general conditions.

\section{Discussion and Review of the Literature}

Traumatic Pneumomediastinum occurs in up to $10 \%$ of cases of blunt chest trauma [4]. It may have different origins but, in more than $95 \%$ of cases, it results from alveolar rupture followed by centripetal air dissection through the pulmonary interstitium into the

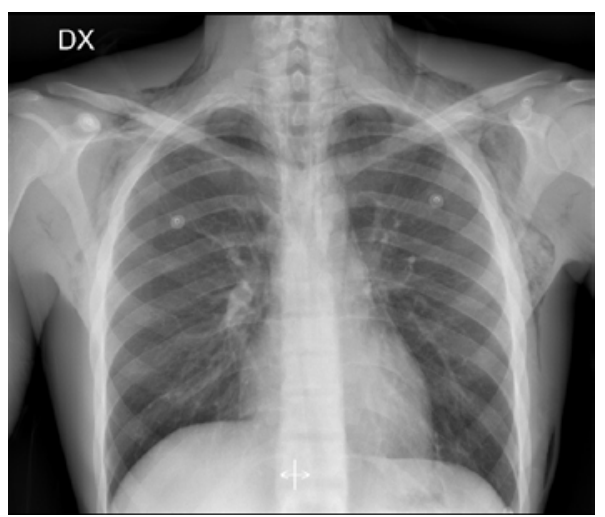

Figure 7: Subcutaneous emphysema reduction.

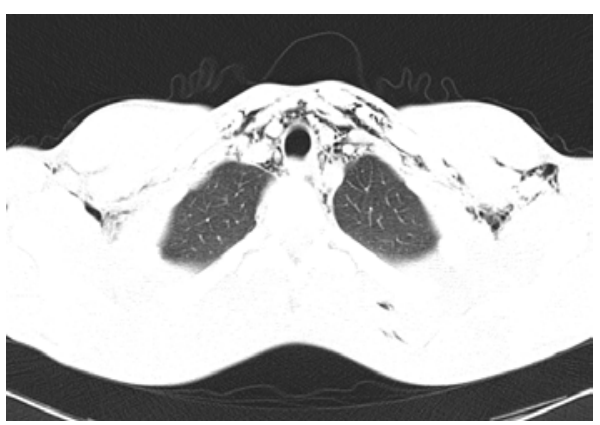

Figure 8: Reduction of pneumomediastinum without pleural and pericardial effusion.

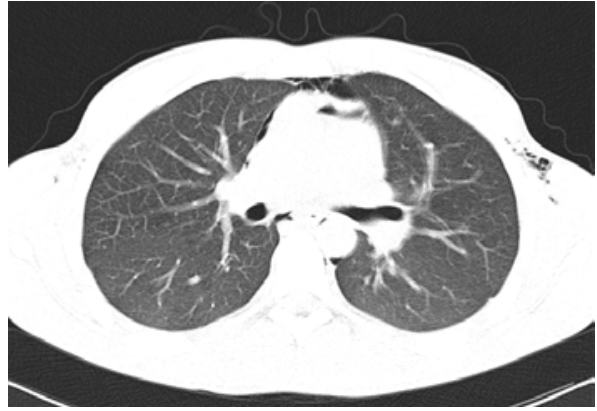

Figure 9: Reduction of pneumomediastinum without pleural and pericardial effusion.

mediastinum. This pathophysiologic process was first described by Macklin in 1939 and further studied by others. In only 2\% of patients pneumomediastinum results from blunt tracheobronchial lesions and its origin from esophageal injuries is rare [5].

Macklin described an experiment on overinflation of cat lungs and he concluded that the high-pressure gradient between alveoli and pulmonary interstitium leads to alveolar rupture. He showed that the air does not reach the mediastinum through the visceral pleura but through the bronchovascular sheats. Cessation of high pressure in the alveoli would stop the passage of air [6].

Macklin effect is observed usually in patients under 60, mainly in healthy young men. Some studies described an increased stiffness of the pulmonary interstitium in the elderly that may prevent air leak and consequently tissue dissection along bronchovascular sheaths [5].

Although chest radiography remains a mainstay for rapid triage, $\mathrm{CT}$ is a more accurate technique for characterization of thoracic injuries $[3,7,8]$.

According to our protocol for high-speed collisions, a blunt chest trauma with severe condition or respiratory compromise immediately undergoes a chest CT survey.

In the Macklin effect, an accurate and early CT examination can show the air dissecting the bronchovascular sheaths and finally spreading into the mediastinum $[4,9]$.

The Wintermark and Schnyder experience has shown the possibility of simultaneous tracheal injury and Macklin effect [5]. Thus, identification of a Macklin effect should not prevent the patient from undergoing a bronchoscopy. In case of spontaneous pneumomediastinum some authors limited bronchoscopy, suggesting to use it selectively in cases with extended pneumomediastinum and suspected of a tracheobronchial rupture $[9,10]$.

In our first patient, the pulmonary situation was so compromised that it was impossible to find any CT signs of Macklin effect and the diagnosis based on different instrumental procedure. In the second case the CT scan performed at our Emergency Department showed few signs of Macklin effect.

We performed bronchoscopy in both cases to rule out any airway lesions.

The self limiting Macklin effect does not affect pulmonary gas exchanges and, consequently, does not alter blood gas analysis result [5]. It's important to remember that during patients evaluation. 
The stable blunt trauma patient with isolated pneumomediastinum caused by Macklin effect, can usually undergo conservative treatment with clinical observation [11-13]. The role of it is mainly to avoid serious complications such as airway obstruction, tension pneumopericardium, pneumothorax, mediastinitis, pneumoperitoneum or in tension pneumomediastinum. The latter was described by Macklin as 'malignant pneumomediastinum'. The air compresses the pulmonary and mediastinal vessels and interferes with respiration by acting on the interstitial tissues of the lung [14]. If not relieved immediately, this condition leads to pulmonary edema and circulatory failure.

Tension pneumomediastinum can also mimic a cardiac tamponade development $[13,15]$.

In our first patient, after pneumomediastinum and pneumoperitoneum decompression, the saturation arose and the vital signs became stable.

The air spread from the mediastinum to the retroperitoneum and finally to the peritoneum could increase intra-abdominal pressure (IAP) $[16,17]$.

The normal adult IAP, measured indirectly by measuring bladder pressure, is from subatmpospheric to less than $10 \mathrm{mmHg}$ in supine position.

The pathologic elevation of IAP is defined as Intra-abdominal hypertension (IAH). IAH may have different grades (Table 1) and it can lead to abdominal compartment syndrome with multiorgan failure. Abdominal Compartment Syndrome (ACS) is defined by a sustained or repeated IAP $>20 \mathrm{mmHg}$ [18-20].

In our first case, the intra-abdominal pressure, measured indirectly by measuring bladder pressure, was $40 \mathrm{~cm} \mathrm{H}_{2} \mathrm{O}(30.7 \mathrm{~mm} \mathrm{Hg})$ and the patient immediately underwent decompressive laparotomy.

The CT scan performed at our department showed air in anterior abdominal region that didn't appear in the previous exam. We think that tracheal intubation with positive pressure ventilation could have maintained high pressure in the alveoli, allowing air passage trough bronchovascular sheats. This situation determined malignant pneumomediastinum and IAH.

\section{Conclusions}

Traumatic Pneumomediastinum occurs in up to $10 \%$ of cases of blunt chest trauma and in more than $95 \%$ of cases it results from Macklin effect.

In any case of post-traumatic pneumomediastinum, the Macklin effect should be suspected and a correct assessment of the thorax CT signs has to be performed.

In cases of extended pneumomediastinum and suspected tracheobronchial rupture, the surgeon could choose to use further

\begin{tabular}{|l|l|}
\hline Intra Abdominal Hypertension (IAH) Grade & \multicolumn{1}{|c|}{ Intra Abdominal Pression (IAP) } \\
\hline Grade I IAH & $12-15 \mathrm{mmHg}$ \\
\hline Grade II IAH & $16-20 \mathrm{mmHg}$ \\
\hline Grade III IAH & $21-25 \mathrm{mmHgh}$ \\
\hline Grade IV IAH & $>25 \mathrm{mmHg}$ \\
\hline
\end{tabular}

Table 1: Intra Abdominal Hypertension Grading. diagnostic procedures, like bronchoscopy, in order to find any other cause of pneumomediastinum. However, this behaviour has to be analysed in wider studies.

When the Macklin effect is confirmed and no other injuries are shown, clinical observation is the treatment of choice since this effect is self-limiting.

In few cases the Macklin effect can cause malignant pneumomediastinum. This life-threatening event must be relieved and treated immediately because it leads to pulmonary edema and circulatory failure.

The air spreading from the mediastinum to the retroperitoneum and finally to the peritoneum can cause an IAH. This event can be showed by clinical observation and indirect measurement of intraabdominal pressure. When IAH has been confirmed, a decompressive laparotomy must be performed to prevent abdominal compartment syndrome and multiorgan failure.

In case of intubation and positive pressure ventilation of patients with traumatic Pneumomediastinum, it's important to pay attention to pulmonary and abdominal situation to avoid serious complications such as Malignant Pneumomediastinum and IAH-ACS.

\section{References}

1. Hamman L (1939) Spontaneous mediastinal emphysema. Bull John Hopkins Hosp 64: 1-21.

2. Laennec (1819) RTH. A treatise on diseases of the chest and on mediate auscultation. (2ndedn), London, UK.

3. Jougon JB, Ballester M, Delcambre F, Mac Bride T, Dromer CE, et al. (2003) Assessment of spontaneous pneumomediastinum: experience with 12 patients. Ann Thorac Surg 75: 1711-1714.

4. Wintermark M, Wicky S, Schnyder P, Capasso P (1999) Blunt traumatic pneumomediastinum: using CT to reveal the Macklin effect. Am J Roentgenol 172: $129-130$.

5. Wintermark M, Schnyder P (2001) The Macklin effect: a frequent etiology for pneumomediastinum in severe blunt chest trauma. Chest 120: 543-547.

6. Macklin CC (1939) Transport of air along sheaths of pulmonic blood vessels from alveoli to mediastinum. Clinical implications. Arch Intern Med 64: 913-926.

7. Kaneki T, Kubo K, Kawashima A, Koizumi T, Sekiguchi M, et al. (2000) Spontaneous pneumomediastinum in 33 patients: yield of chest computed tomography for the diagnosis of the mild type. Respiration 67: 408-411.

8. Caceres M, Ali SZ, Braud R, Weiman D, Garrett HE Jr (2008) Spontaneous pneumomediastinum: a comparative study and review of the literature. Ann Thorac Surg 86: 962-966.

9. Sakai M, Murayama S, Gibo M, Akamine T, Nagata O (2006) Frequent cause of the Macklin effect in spontaneous pneumomediastinum: demonstration by multidetector-row computed tomography. J Comput Assist Tomogr 30: 92-94.

10. Mondello B, Pavia R, Ruggeri P, Barone M, Barresi P, et al. (2007) Spontaneous pneumomediastinum: experience in 18 adult patients. Lung 185: 9-14.

11. Mondello B, Barone M, Barresi P, Familiari D, Micali V, et al. (2009) Etiology, pathophysiology and management of post-traumatic pneumomediastinum: our experience. G Chir 30: 365-368.

12. Bouwen L, Bosmans E (1997) Posttraumatic pneumomediastinum: not always cause for alarm. Acta Chir Belg 97: 145-147.

13. Weissberg D, Weissberg D (2004) Spontaneous mediastinal emphysema. Eur J Cardiothorac Surg 26: 885-888.

14. Macklin MT, Macklin CC (1944) Malignant interstitial emphysema of the lungs and mediastinum as an important occult complication in many respiratory 
Citation: Assenza M, Passafiume F, Valesini L, Centonze L, Romeo V, et al. (2012) Pneumomediastinum and Pneumoperitoneum after Blunt Chest Trauma: The Macklin Effect. J Trauma Treatment 1:107. doi:10.4172/2167-1222.1000107

Page 5 of 5

diseases and other conditions: interpretation of clinical literature in light of laboratory experiment. Medicine 23: 281-358.

15. Bejvan SM, Godwin JD (1996) Pneumomediastinum: old signs and new signs. AJR Am J Roentgenol 166: 1041-1048.

16. Canivet JL, Yans T, Piret S, Frere P, Beguin Y (2003) Barotrauma-induced tension pneumoperitoneum. Acta Anaesthesiol Belg 54: 233-236.

17. Gardner-Thorpe D, Maddox PR (1999) Idiopathic pneumoperitoneum following blunt chest trauma: a case report. Injury 30: 511-513.

18. An G, West MA (2008) Abdominal compartment syndrome: a concise clinical review. Crit Care Med 36: 1304-1310.
19. Malbrain ML, Cheatham ML, Kirkpatrick A, Sugrue M, Parr M, et al. (2006) Results from the International Conference of Experts on Intra-abdominal Hypertension and Abdominal Compartment Syndrome. I. Definitions. Intensive Care Med 32: 1722-1732.

20. Cheatham ML, Malbrain ML, Kirkpatrick A, Sugrue M, Parr M, et al. (2007) Results from the International Conference of Experts on Intra-abdominal Hypertension and Abdominal Compartment Syndrome. II. Recommendations. Intensive Care Med 33: 951-962. 